dardized methods but also of many others developed during the past 10 years. It is divided into an introductory section on the cell and methods of examining cells (nine pp.) and further sections on fixation, processing, and section cutting (70 pp.), stains, impregnations, and mountants (160 pp.), special procedures, including autoradiography and microincineration (11 pp.), museum technique ( $27 \mathrm{pp}$.), and the microscope (55 pp.). Each section includes an appropriate amount of information on the theories underlying the techniques recommended.

A wide range of staining methods is described, almost always simply and adequately, and often with added details, small in themselves but important in practice, that clearly reflect the author's own experience in the laboratory. Several useful tables are included, amongst them a stain solubility chart, buffer tables, and schemes for identification of lipid and P.A.S.-positive materials. The section on the microscope includes descriptions of the compound, darkground, fluorescence, polarizing, phase-contrast, and interference machines, and even a short note on the electron microscope. Though 55 pages long, this section makes available in one place much information that has otherwise to be sought in several. The chapters on museum technique will be useful to workers in many laboratories. The manufacture of perspex specimen jars is not difficult (though finding time may be!): the clear instructions here, combined with a visit to some laboratory already making jars, should bring it within the range of any competent technician.

In a text almost innocent of misprints (there is one on p. 292, second last line) it is surprising to find so many errors in proper names: Perl's for Perls's (throughout, including the frontispiece), Grubler for Grübler (throughout), Heiffor for Heiffer (pp. 89-91, though correct in index), McNanus for McManus (in bibliography, though correct in text), Hutchinson for Hutchison (in index and bibliography, though correct in text), and a misrendering of Dr. A. G. E. Pearse's name in the bibliography. In figure 31 the legends for posterior horn and posterior root have been transposed.

A few further points might merit attention in a second edition. The corrosive effects of mercuric chloride on metal (p. 27) can be resisted by containers of "monel" metal available for use in automatic tissue processing machines. Gelatin embedding may be useful for uterire curettings (p. 79), but there should rarely be difficulty with ordinary paraffin techniques. The section on knife sharpening ( $p p$. 95-97) could usefully include some mention of the flat disc or turntable type of sharpener so widely and successfully used in the U.S.A. The statement (p. 217) that fixation is not critical for the demonstration of fibrin does not apply to the picro-Mallory methods: the best results follow two to three weeks' fixation in mercuric chloride. Enough has by now been discovered about mast cells to make obsolete the statement (p. 294) that "the function of these cells is not known ": and it is an over-simplification to say that the epidermis consists of two layers (p. 332).

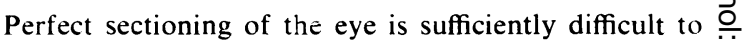
warrant greater technical detail than there is on $\overrightarrow{\vec{F}}$

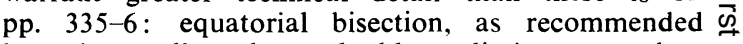
here, is usually a less valuable preliminary cut than 0 two slices that " take off the top and bottom," leaving 음 the whole of the cornea, lens, and optic nerve in one flat circular block.

In general, however, this is a book that well $\varrho$ deserves a place on the shelves of any histopatho- $\%$ logical laboratory. Indeed, a laboratory would do $\overrightarrow{0}$ well to have two copies, one for reference, the other for borrowing, for the author has had in mind the $\vec{\omega}$ needs of candidates for the final examination of the $\stackrel{\omega}{\sigma}$ I.M.L.T. It has clear type, a pleasing format, and a waterproof, acid-resistant binding.

W. W. PARK. $\overrightarrow{\dot{\omega}}$

The Biologic Basis of Cancer Management. By $\dot{\sim}_{\infty}$ Freddy Homburger. (Pp. xviii $+354 ; 39$ tables, 10 figures. 75s.) London: Cassell. 1958.

The title of this book is promising. So is its dedi- $\vec{r}$ cation, "To Gin," and so also are the forewords, three $>$ of them, by a pathologist, a research worker, and a surgeon.

In the preface which follows, the author explains of how the book came to be written; in reply, it seems. to questions put to him as a "cancer co-ordinator." $\mathrm{He}$ is disarmingly modest about the wisdom of writing it: "the idea of the biologic basis of cancer management was indeed rejected by a publisher because of the opinion of eminent consultants that no $\frac{\circ}{\mathbb{D}}$ one person could write such a book." Unfortunately they were right.

In the first place the title is very misleading. Thus 3 126 pages are devoted to the aetiology of cancer compared with four to the principles of surgery. The principles of radiotherapy receive 10 pages but contain only a scant reference to the variable radio- $\frac{0}{0}$ sensitivity of tissues and their derived tumours. McWhirter's treatment of breast carcinoma is men-3. tioned but not discussed, nor is any estimate attempted of the true value of early surgery or of periodic check-ups in the detection of early cancer.

By deleting the word "management" perspective $\stackrel{\circ}{?}$ is restored but many weaknesses remain. Over-con- $\frac{D}{O}$ densation has led to superficiality and in places also to imbalance. Two pages on the relation of smoking to lung cancer contain no relevant figures and no mention of Wynder and Graham or Doll and $\mathbb{O}$ Bradford Hill. This enables Dr. Homburger to $\mathrm{N}$ remain securely on the fence-perhaps he is a heavy $\sigma$ smoker. Elsewhere we have sentences such as: "It appears from the rate of cancer incidence that about $\stackrel{0}{c}$ $20^{\circ}$ of the population are susceptible." To what ? to the present level of environmental carcinogens? and in what life-span? The sentence is either a $\underset{T}{T}$ tautology or untrue, since, as the author points out further on, if we live long enough $80 \%$ of us will develop cancer of the prostate.

In addition there are far too many errors ; " mega- $\frac{\varrho}{9}$ karyocytes" for "megaloblasts" on p. 141 is a glaring example, and table 8 is full of them.

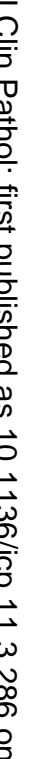


In fairness it must be said that the second section on "the biologic behaviour of cancer" contains some interesting material, this being Dr. Homburger's own field of study. But the relative merits of the middle do not redeem the whole book.

\section{Humphrey KaY.}

Comparative Aspects of Haemolytic Disease of the Newborn. By G. Fulton Roberts. (Pp. xi 199. 17s. 6d.) London: William Heinemann Medical Books. 1957.

For his first chapter Dr. Fulton Roberts has unearthed some interesting historical facts about haemolytic disease of the newborn. As early as the seventeenth century the occurrence of more than one case of neonatal jaundice in a family had been noted. In the middle of the nineteenth century a veterinarian, in describing some cases of neonatal icterus in newborn foals, was put in mind of a neighbour who had lost several successive infants from jaundice.

The association of anaemia with severe neonatal jaundice was noted by Auden in 1905, and earlier (1892) Ballantyne described the association of anaemia with hydrops foetalis. Recognition that icterus gravis and hydrops were linked was possibly delayed by the fact that one form or the other tends to recur in the same family, so that a woman may have a dozen badly jaundiced infants in a row without one hydropic infant. However, between 1922 and 1931 several authors concluded that there was a definite disease entity which might be manifested by jaundice or oedema. The ground was thus prepared for Diamond, Blackfan, and Baty's well-known review, published in 1932 .

The rest of the book is devoted to a detailed survey of the published work on haemolytic disease of the newborn in man and animals. There are a few statements to which exception may be taken: it is not the " oxygen carying power of each red cell" which " is suddenly improved at birth" (page 36) but the oxygen saturation. It is a little misleading to say (pages 43 and 44) "How vitamin $K$ promotes the hyperbilirubinaemia in man is not clear" since in Allison's first reported cases signs of haemolytic anaemia were noted. The two-component curve of elimination of incompatible cells which has been described in man can hardly be due to exhaustion of complement (page 134) since it is observed when less than $1 \mathrm{ml}$. of cells is injected. These and a few similar passages do not seriously detract from the value of the book, which will be found a most useful source of references to anyone interested in haemolytic disease.

\section{P. L. Mollison.}

Burns : Pathology and Therapeutic Applications. By Simon Sevitt. (Pp. xii +364 ; 85 figures. 37s. 6d.) London: Butterworth. 1957.

This small, convenient, well-written, and wellproduced volume brings together almost everything that is known concerning " the pathology and disordered physiology after burning." The physical aspects of burning, the histopathology of the lesions, including healing and disturbances of healing and the bacteriology, epidemiology, and control of infection, are dealt with in detail. Chapters follow dealing fully with mortality and causes of death, the physiopathology of burn shock, other metabolic effects, and the effects in each of the systems of the body. Finally there are accounts of the special features of flash, radiation, electrical, and chemical burns, and full author and subject indices.

Throughout the book there is the fullest consideration of therapeutic relationships and full documentation of all the aspects discussed. It would be difficult to imagine a more complete and lucid account of a limited subject. The book provides an unparalleled source for references on its subject and must prove invaluable for all-clinicians as well as pathologists -who are regularly concerned with the handling of these distressing injuries.

\section{T. Crawford.}

Fluid Balance in Surgical Practice, 2nd ed. By L. P. Le Quesne. (Pp. vii +140 ; 42 figures. 20s.) London: Lloyd-Luke. 1957.

In presenting the second edition of this popular book, the author has revised the text to correct a disproportion between the sections in the original work and to incorporate recent advances. The monograph includes an account of the physiology of the body fluids and the metabolic response to surgery, with sections on water, salt, and potassium depletion and brief chapters on renal failure, water and salt excesses, nutritional problems, and fluid balance in children. An appendix giving a number of illustrative case histories is a useful feature.

This is indeed a wide field to be covered in 140 pages, but the author has successfully achieved this by selecting a practical approach with emphasis on the recognition and management of disturbances in fluid and electrolyte balance.

It is considered that acid base upsets have received undue attention in the past, and it is perhaps unfortunate that little space has been devoted to their consideration. The reader seeking information on this topic will therefore be disappointed. One might also have expected some mention of the use of plasma substitutes such as dextran in patients with severe circulatory collapse. As a routine basic fluid intake post-operatively, the generous figure of $3,000 \mathrm{ml}$. per 24 hours is recommended, a dose that would appear in some cases to carry a risk of water intoxication.

Though primarily intended for the practising surgeon, who cannot afford to be ignorant of the principles and considerable practical information contained therein, this book includes much that will interest and enlighten the laboratory worker.

H. W. C. Auld. 